a year. No one expects spending on this scale to continue in the current tight fiscal environment. Indeed, the state of the economy only makes the case stronger for clear long-term policies, which will help to ensure that spending is wise.

Radical thinking on the future direction of universities will be needed as part of this long-term vision. But Labour's more recent higher-education framework, published at the beginning of this month, is less inspiring than its 2004 document. The framework hints that the Labour government would like to see funding for university research further concentrated in the top universities and in key strategic science areas, but the government lacks the confidence to say what it really wants. There are legitimate questions to be asked about whether Britain needs more than 100 universities all chasing after the same limited pot of research funds, and whether this money would be better spent across fewer of those institutions. At least Labour's whiffs of a stance on these issues are better than the deafening silence of the Conservative Party.

Rightly, both Labour and the Conservatives remain committed to the current dual funding system for the foreseeable future. It is through this system, in which universities win a pot of research funding from the government in line with their demonstrated research excellence, and also competitively gain funding from research councils, that universities have the freedom to plan and invest as they see fit.

Creative thinking is also sorely needed to improve the exploitation of Britain's research base. This issue has long been on the agenda and Labour has taken some strides forwards, including establishing the Technology Strategy Board, which provides competitive funding for high-tech businesses. But significant increases in private investment in R\&D are still lacking, and are as important as ever in the long term.

To be fair, the Conservatives have signalled a desire to support the high-tech commercial sectors, establishing a task force led by James Dyson, a British inventor, that will report its recommendations on how to improve UK innovation to the party before the general election. But its agenda is a worrying indication of the party's unsophisticated appreciation of the interplay between science and innovation: there is no reference to the importance of continuing to support the research needed to yield the discoveries on which products and services are based.

As Britain's next general election approaches, Labour can point to a strong record of personal commitment to science and sciencebased enterprise from its leaders and of supportive actions. So far, the Conservatives, in contrast, are a vision-free zone.

\section{Getting what you pay for}

\section{The US Food and Drug Administration cannot fulfil} its mandate without a serious funding boost.

$$
\text { T }
$$

he US Food and Drug Administration (FDA) is in capable new hands. Its commissioner, Margaret Hamburg, a Harvardtrained physician six months into her tenure, brings to the job both a broad experience in science, public health and biosecurity (see page 406) and an ability to handle multiple, simultaneous demands - a skill she displayed as New York City's youngest health commissioner.

For all her abilities, however, Hamburg is struggling to steer an underpowered ship that is loaded to the gunwales. The 103-year-old agency, based in Silver Spring, Maryland, has never before had so many demands placed on it, nor has its budget ever been so constrained relative to its duties. Between 2001 and 2007, for example, the number of US food-manufacturing plants under the FDA's jurisdiction increased from about 51,000 to more than 65,000, yet the number of staff in its foods programme fell from 3,167 to 2,757 . At current inspection rates, any given domestic food company faces a less than one-in-four chance of being inspected once in seven years. And that looks frequent compared with the agency's estimated average inspection rate for foreign manufacturers of medium-risk medical devices: once every 27 years.

It is true that the FDA's funding has been boosted since 1993 by user fees paid by drug- and device-makers. In 2009, such fees amounted to nearly $23 \%$ of the agency's $\$ 2.7$-billion budget. But this influx has, paradoxically, taken the pressure off Congress to fund the many mandates it continues to heap on the agency. For instance, the FDA is expected to monitor the accuracy of direct-to-consumer advertisements by drug companies, and the promotional materials they send to physicians. But in 2008, Congress gave enough money to fund only 55 staff for this job. With some 71,000 industry submissions in 2008 , those employees can cope with only a small fraction. Similarly, because drug and device fees are dedicated largely to funding reviews for market approval, other functions at the agency, most notably food safety, have received short shrift.

Calls for more cash inevitably raise red flags in this era of ballooning deficits, but the imbalance between the FDA's means and its responsibilities makes the need inescapable. A bipartisan group including six former FDA commissioners and three former heads of the agency's parent department, the Department of Health and Human Services, has publicly urged Congress to boost the agency's appropriations. So have almost all FDA-regulated industries, including the Grocery Manufacturers Association, the Medical Device Manufacturers Association and most major drug companies, as well as dozens of patient groups.

How much extra money is enough? The FDA's science board was asked the same question by Congress in late 2007 after the board issued a scathing report on the agency's eroding scientific capabilities (see Nature 450, 1143; 2007). To set things right, the board concluded last year, Congress would need to add \$450 million to the agency's budget in 2010, and $\$ 460$ million each year between 2011 and 2013.

The administration of President Barack Obama has asked Congress for a further $\$ 295$ million for the agency in 2010 , which would bring its congressional appropriations to $\$ 2.3$ billion - less than what is needed, according to the science board's estimates, but "a good start", as Hamburg told Nature earlier this month. Congress should provide at least that much, and make plans to boost that figure in subsequent years.

Historically, it has taken crises to goad legislators into giving the FDA the money and muscle it needs - a notable example being the poisonous cough syrup that killed more than 100 people in 1937, and led to the 1938 enactment of the Federal Food, Drug, and Cosmetic Act, which still forms the basis of the FDA's authority. Congress shouldn't wait for the next crisis. 